\title{
Functional significance of repressor element 1 silencing transcription factor (REST) target genes in pancreatic beta cells
}

\author{
D. Martin • F. Allagnat $\cdot$ G. Chaffard $\cdot$ D. Caille $\cdot$ \\ M. Fukuda $\cdot$ R. Regazzi • A. Abderrahmani • \\ G. Waeber $\cdot$ P. Meda $\cdot$ P. Maechler $\cdot$ J.-A. Haefliger
}

Received: 17 October 2007 / Accepted: 19 February 2008 / Published online: 3 April 2008

(C) Springer-Verlag 2008

\begin{abstract}
Aims/hypothesis The expression of several neuronal genes in pancreatic beta cells is due to the absence of the transcription factor repressor element 1 (RE-1) silencing transcription factor (REST). The identification of these traits and their functional significance in beta cells has only been partly elucidated. Herein, we investigated the biological consequences of a repression of REST target genes by expressing REST in beta cells.

Methods The effect of REST expression on glucose homeostasis, insulin content and release, and beta cell mass was
\end{abstract}

Electronic supplementary material The online version of this article (doi:10.1007/s00125-008-0984-1) contains supplementary material, which is available to authorised users.

D. Martin · F. Allagnat · G. Waeber · J.-A. Haefliger

Department of Medicine, University Hospital, CHUV,

Lausanne, Switzerland

G. Chaffard $\cdot$ D. Caille $\cdot$ P. Meda $\cdot$ P. Maechler

Department of Cell Physiology and Metabolism,

University of Geneva, CMU,

Geneva, Switzerland

\section{Fukuda}

Graduate School of Life Sciences, Tohoku University,

Sendai, Japan

R. Regazzi · A. Abderrahmani

Department of Cell Biology and Morphology,

University of Lausanne,

Lausanne, Switzerland

J.-A. Haefliger $(\bowtie)$

Department of Medicine,

Laboratory of Molecular Medicine,

University Hospital, 19-135S,

CHUV-1011 Lausanne, Switzerland

e-mail: Jacques-Antoine.Haefliger@chuv.ch analysed in transgenic mice selectively expressing REST in beta cells. Relevant target genes were identified in INS-1E and primary beta cells expressing REST.

Results Transgenic mice featuring a beta cell-targeted expression of REST exhibited glucose intolerance and reduced beta cell mass. In primary beta cells, REST repressed several proteins of the exocytotic machinery, including synaptosomal-associated protein (SNAP) 25, synaptotagmin (SYT) IV, SYT VII, SYT IX and complexin II; it impaired first and second phases of insulin secretion. Using RNA interference in INS-1E cells, we showed that SYT IV and SYT VII were implicated in the control of insulin release.

Conclusions/interpretation The data document the critical role of REST target genes in pancreatic beta cells. Specifically, we provide evidence that the downregulation of these genes is detrimental for the exocytosis of large dense core vesicles, thus contributing to beta cell dysfunction and impaired glucose homeostasis.

Keywords Exocytosis - Insulin secretion · RE-1 ·

RE-1 silencing transcription factor $\cdot$ REST $\cdot$ Synaptotagmins . Transgenic mice

$\begin{array}{ll}\begin{array}{l}\text { Abbreviations } \\ \text { Ad-GFP }\end{array} & \text { GFP-encoding adenovirus } \\ \text { Ad-REST } & \text { REST-encoding adenovirus } \\ \text { BCH } & \beta \text {-2-aminobicyclo [2.2.1] heptane- } \\ & \text { 2-carboxylic acid } \\ \text { CX36 } & \text { connexin 36 } \\ \text { GFP } & \text { green fluorescent protein } \\ \text { hGH } & \text { human growth hormone } \\ \text { IBMX } & \text { 3-isobutyl-1-methylxanthine } \\ \text { IPGTT } & \text { intraperitoneal glucose tolerance test } \\ \text { KRBH } & \text { KRB HEPES }\end{array}$




$\begin{array}{ll}\text { LDCV } & \text { large dense core vesicles } \\ \text { MUNC-18-1 } & \text { UNC-18 homologue 1 } \\ \text { NSF } & N \text {-ethylmaleimide-sensitive factor } \\ \text { RE-1 } & \text { repressor element } 1 \\ \text { REST } & \text { RE-1 silencing transcription factor } \\ \text { RIP II } & \text { rat insulin II promoter } \\ \text { SiRNA } & \text { small interfering RNA } \\ \text { SNAP } & \text { synaptosomal-associated protein } \\ \text { SNARE } & \text { soluble } N \text {-ethylmaleimide-sensitive factor } \\ & \text { attachment protein receptor } \\ \text { SREBP-1 } & \text { sterol regulatory element-binding protein-1 } \\ \text { SYT } & \text { synaptotagmin }\end{array}$

\section{Introduction}

The transcription factor repressor element 1 (RE-1) silencing transcription factor (REST), also known as neuron-restrictive silencing factor, has been implicated in the control of glucoseinduced insulin secretion in the $\beta \mathrm{TC} 3$ cell line [1]. This GLIKruppel zinc finger transcription factor was first described as a silencer of neuronal genes outside the central nervous system, since its expression is restricted to non-neuronal cells and undifferentiated neural progenitors, allowing genes encoding fundamental neuronal traits to be exclusively expressed in mature neurons $[2,3]$. Target genes possess a 21 bp cis element called RE-1 or neuron restrictive silencer element, to which REST binds to inhibit expression. Initial studies indicated that many REST target genes contribute to synaptic plasticity/remodelling, inasmuch as REST regulates the expression of synaptic vesicle proteins [4], voltagesensitive ion channels [2] and neurotransmitter receptors [5, 6]. However, increasing evidence suggests that the significance of the REST/RE-1 system is diverse in embryonic and adult cells and depends on the range of target genes that REST interacts with. Accordingly, a bioinformatic analysis recently revealed about 1,800 putative REST target genes within the human genome, with attributed roles ranging from transcriptional regulation through to metabolism and various aspects of neuronal function [7]. Previous reports have identified some of these target genes and their function in and outside the nervous system. Thus, it is now documented that REST target genes are involved in the reactivation of the fetal cardiac gene programme in hypertrophied and failing hearts [8], and modulate the vascular plasticity/remodelling of human neointimal hyperplasia [9].

Pancreatic beta cells, which lack REST [10], also express a number of REST target genes. However, it remains to be established how these genes participate in beta cell function. Investigating this molecular mechanism, we previously showed that in beta cells REST controls the expression of two neuron-specific genes that code for connexin 36 (CX36), a gap junction-forming protein participating in control of insulin secretion [11], and islet brain-1, a scaffold protein protecting beta cells against apoptosis via the c-Jun Nterminal kinase signalling pathway [12]. Since the whole set of REST target genes is involved in the control of insulin secretion in vitro [1], we have now examined the in vivo consequences of a gain of function of REST and have identified additional target genes that are significant to beta cell function. We show that transgenic mice specifically expressing REST in beta cells exhibit glucose intolerance and defective insulin release. We further demonstrate that REST expression affects both triggering and amplifying pathways of insulin secretion, by impairing the expression of proteins of the exocytotic machinery, including the hitherto neglected synaptotagmin (SYT) IV and VII. These data demonstrate the crucial role of REST targets in the control of insulin release and suggest that the downregulation of these genes may contribute to the pathophysiology of beta cell defects.

\section{Methods}

Transgenic mice Transgenic mice specifically expressing REST in the beta cells were obtained by pronuclear injection of $\mathrm{C} 57 \mathrm{Bl} / 6$ zygotes with a SacII/XhoI fragment consisting of $660 \mathrm{bp}$ of the rat insulin II promoter (RIP II) [13], separated from the full length human REST cDNA [12] by the rabbit $\beta$-globin intron (Fig. 1a). Three positive founder mice were successfully bred with C57BL/6 control mice to generate transgenic animals. Our institutional review committee for animal experiments approved all the procedures for mice care, surgery and animal killing.

Immunohistochemistry Pancreases were fixed in 4\% (wt/vol.) paraformaldehyde, equilibrated overnight in $15 \%$ (wt/vol.) sucrose, embedded in $15 \%$ sucrose $-7.5 \%$ (wt $/ \mathrm{vol}$.) gelatin and quickly frozen in methylbutane/liquid nitrogen. Cryosections were incubated overnight at $4^{\circ} \mathrm{C}$ with either polyclonal rabbit antibodies against human REST or polyclonal guinea pig antibodies against insulin. Primary antibodies were detected using appropriate fluorescein or rhodamine-conjugated antibodies. Sections were viewed on a fluorescence microscope (Leica, Nidau, Switzerland).

Electron microscopy Pancreas fragments were fixed in a $2.5 \%$ (vol./vol.) glutaraldehyde solution in $0.1 \mathrm{~mol} / 1 \mathrm{phos}-$ phate buffer ( $\mathrm{pH} 7.4)$, postfixed in $1 \%$ (wt/vol.) osmium tetroxide in the same buffer, dehydrated and embedded in Epon [14]. Thin sections were examined in a Philips CM10 electron microscope (Philips, Eindhoven, the Netherlands).

Glucose tolerance and plasma insulin Male mice of 12 to 16 weeks were fasted for $14 \mathrm{~h}$ before blood samples were 
a

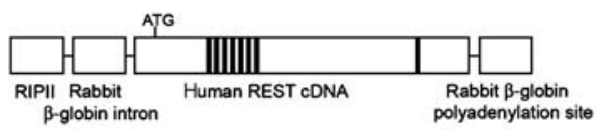

b
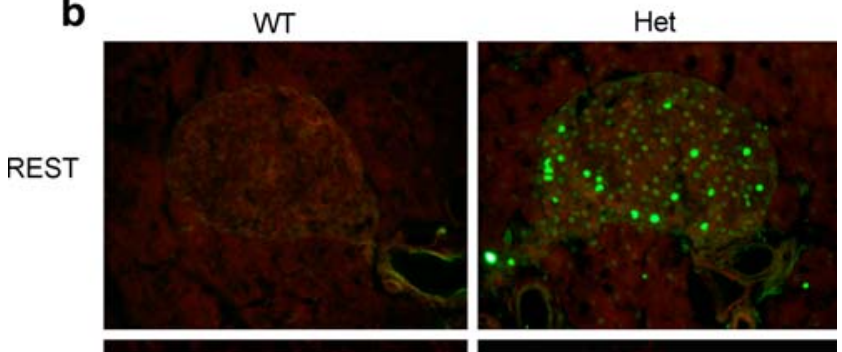

Ins

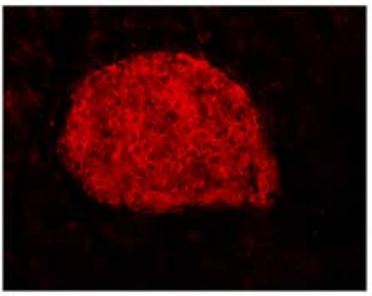

C
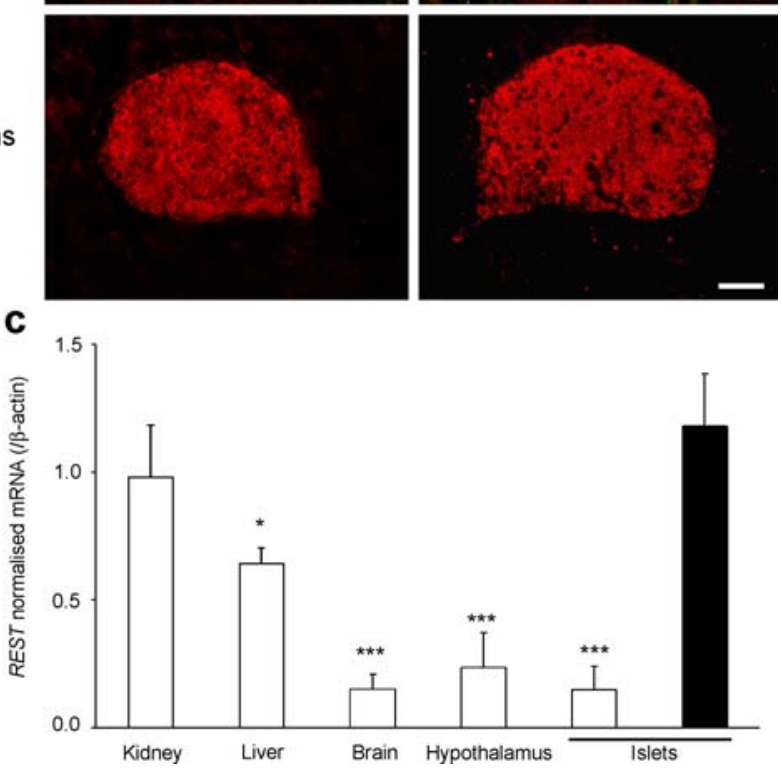

Fig. 1 Generation of transgenic mice expressing REST in beta cells. a The construct used to generate RIP-REST transgenic mice contained the full-length human REST cDNA, surrounded by rabbit $\beta$-globin intronic and polyadenylation sequences, and fused to the RIP II. Solid bars, the nine-zinc fingers; ATG, start codon of human REST cDNA. b RIP-REST mice featured morphologically normal pancreatic islets. Immunostaining using specific antibodies against human REST (in green) and insulin (in red) demonstrated that REST was specifically produced in the nucleus of beta cells of heterozygous (Het) RIPREST but not wild-type (WT) mice. The corresponding insulin staining (Ins) is shown. Scale bar, $30 \mu \mathrm{m}$. c Quantitative RT-PCR analysis of mRNA levels of murine and human REST in RIP-REST mice. White columns show levels of endogenous murine Rest. The black column shows levels of the human REST transgene. No human REST expression was found outside pancreatic islets. Results are means \pm SEM of four independent experiments. ${ }^{*} p<0.05, * * * p<0.001$ versus values for human REST mRNA levels

collected from the tail vein at 0 (fasting blood sample), 15, 30 and $120 \mathrm{~min}$ after an intraperitoneal injection of glucose $(2 \mathrm{~g} / \mathrm{kg}$ body weight as a $20 \%$ solution). Blood glucose levels were measured with a Glucometer (Bayer Healthcare, Zurich, Switzerland). Plasma insulin levels from the same time points were determined by ELISA (Mercodia, Uppsala, Sweden).

Cell line and mouse islet isolation The rat insulinoma cell line INS-1E was maintained in RPMI 1640 medium, as previously described [15]. Islets of Langerhans of adult C57BL/6 male mice, weighing 25 to $30 \mathrm{~g}$, were isolated and cultured as previously described [15].

Insulin secretion INS-1E cells were seeded in 12-well plates and cultured for $48 \mathrm{~h}$. Isolated islets were cultured overnight in non adherent dishes. Cells and islets were infected with adenoviruses as previously described [11], with a multiplicity of infection of 10 and 15, respectively. As judged by immunofluorescence and quantitative PCR detection of the REST transgene, this procedure typically resulted in the efficient transduction of 70 to $80 \%$ INS-1E cells and 30 to $40 \%$ primary islet cells. Insulin secretion of INS-1E cells and mouse islets perifusion were assessed in KRB-HEPES (KRBH) supplemented with the indicated stimuli, as published [16]. When $30 \mathrm{mmol} / \mathrm{l} \mathrm{KCl}$ was added in the experiments testing diazoxide, the $\mathrm{NaCl}$ concentration of the medium was reduced to $105 \mathrm{mmol} / \mathrm{l}$. Glucose, leucine, $\beta$-2-aminobicyclo [2.2.1] heptane-2-carboxylic acid (BCH), forskolin, 3-isobutyl-1methylxanthine (IBMX) and diazoxide were purchased from Sigma (Fluka Chemie, Buchs, Switzerland).

Cell and mitochondrial membrane potentials INS1-E cell and mitochondrial membrane potentials were monitored using $100 \mathrm{nmol} / \mathrm{l}$ bis-oxonol and $10 \mu \mathrm{g} / \mathrm{ml}$ rhodamine-123 (Molecular Probes, Eugene, OR, USA), respectively, as previously described [17].

Calcium measurements Cytosolic calcium was monitored in INS-1E cells loaded for 90 min with $2 \mu \mathrm{mol} / 1$ Fura-2AM (Teflab, Austin, TX, USA) in $\mathrm{KRBH}$ at $37^{\circ} \mathrm{C}$. Ratiometric measurements of Fura-2 fluorescence were performed in a platereader fluorimeter (Fluostar Optima; BMG Labtechnologies, Offenburg, Germany) with filters set at $340 / 380 \mathrm{~nm}$ for excitation and $510 \mathrm{~nm}$ for emission.

Chromatin immunoprecipitation assay INS-1E cells were cross-linked with $1 \%$ (wt/vol.) formaldehyde for $30 \mathrm{~min}$ and the reaction was stopped by addition of $0.125 \mathrm{~mol} / \mathrm{l}$ glycine. Pelleted cells were lysed in an SDS buffer and submitted to sonication to obtain the desired chromatin length ( $\sim 500 \mathrm{bp})$. Chromatin was precleared by addition of blocked protein A Sepharose (Amersham Bioscience Europe, Otelfingen, Switzerland) and the supernatants were immunoprecipitated overnight at $4^{\circ} \mathrm{C}$ with either polyclonal rabbit antibodies specific to human REST [11] or to irrelevant sterol regulatory element-binding protein-1 (SREBP-1) (Santa Cruz Biotechnology, Santa Cruz, CA, USA). The protein-antibody complexes were collected by addition of protein A Sepharose for $1 \mathrm{~h}$ and then washed. The protein-DNA complexes were eluted, treated with RNAseA and proteinase $\mathrm{K}$ and then the cross-links were reversed overnight at $65^{\circ} \mathrm{C}$. DNA was submitted to PCR amplification of rat RE-1 flanking 
sequences using specific primers (see Electronic supplementary material $[\mathrm{ESM}]$ Table 1$)$.

RNA isolation and northern blotting RNA isolation and northern blot analysis were performed as previously described [15]. Transcripts levels were revealed using specific probes for rat $C x 36$ (also known as Gja9), $\beta$-actin [11], rat Munc18-1 (also known as Stxbp1), Syntaxin 1A and Rab3a. For the other genes, probes were obtained with cDNA from INS-1E cells or rat brain, which was amplified with specific primers (ESM Table 2).

Real-time RT-PCR Quantitative RT-PCR was performed using a kit (SYBR Premix Ex Taq PCR Kit TaKaRa; Axon Lab, Le Mont-sur-Lausanne, Switzerland) in a Lightcycler (Roche Diagnostics, Mannheim, Germany), as previously described [15]. cDNAs were amplified using specific primers (ESM Table 3).

Western blotting Western blots were performed as previously described [15]. Specific protein levels were revealed with polyclonal rabbit antibodies against: CX36 [11], synaptosomal-associated protein (SNAP) 25 (kindly provided by $\mathrm{H}$. Hirling, EPFL, Lausanne, Switzerland) and SYT IV. Monoclonal antibodies against $\beta$-actin (Fluka Chemie) were used to normalise the signals.

SYT IV, SYT VII and REST silencing vectors Specific small interfering RNA (siRNA) were designed as follows: for rat Syt4, the sense target sequence 5'GAAGCACAAAGT GAAAACCA3' was deduced from the reported mouse sequence [18]; for rat $S y t 7$ the sense sequence 5'TCAT CACCGTCAGCCTTAG3' was selected according to a previous publication [19]; for REST, the sense sequence $5^{\prime}$ GGAACCTGTTGAGAAGGGA3' was selected using the siRNA Target Finder (Ambion, Austin, TX, USA). Two complementary DNA fragments encoding the target sequence and separated from the reverse complement by a short spacer were synthesised by Microsynth (Balgach, Switzerland). The two fragments were annealed and cloned downstream of the H1-RNA promoter of the pSuper vector, using BglII-HindIII sites. BamHI-HindIII fragments containing the siRNA constructs were subcloned in a plasmid (pXGH) encoding human growth hormone (hGH).

Human growth hormone secretion INS-1E cells were transiently transfected with the pXGH vector to use hGH as a reporter for secretion or with the $\mathrm{pXGH}$ containing one of the specific siRNAs. At $72 \mathrm{~h}$ after transfection, secretion was assessed in KRBH supplemented with $20 \mathrm{mmol} /$ 1 glucose, $10 \mu \mathrm{mol} / 1$ forskolin and $100 \mu \mathrm{mol} / 1 \mathrm{IBMX}$, and measured as published [20].
Statistical analysis Data were expressed as mean $\pm \mathrm{SD}$ or SEM. Differences between means were assessed using Student's $t$ test. Statistical significance was defined at a value of $p<0.05, p<0.01$ and $p<0.001$.

\section{Results}

Transgenic mice featuring a beta cell-targeted expression of REST exhibit reduced insulin content and altered tolerance to glucose To generate transgenic mice producing REST in pancreatic beta cells, we inserted a transgene consisting of the RIP II upstream of the full-length human REST cDNA (Fig. 1a). Examination of pancreas sections revealed morphologically normal islets in both wild-type and RIP-REST mice. However, in contrast to their control littermates, RIP-REST mice produced REST in the nuclei of the islets of Langerhans (Fig. 1b). Parallel immunostaining of insulin (Fig. 1b) confirmed that this expression was restricted to beta cells. Quantification of mRNA by realtime PCR revealed that levels of the human REST transgene achieved in the islets of RIP-REST mice were comparable to those of endogenous Rest in kidney. In contrast, no expression of the REST transgene was detected in the other tested organs (Fig. 1c). A much lower expression of the native murine Rest was detected in brain and islets, probably reflecting the non-neuroendocrine cells of these organs (Fig. 1c). Electron microscopy revealed normal distribution of the insulin-containing beta cells within the islets of both wild-type (Fig. 2a) and RIP-REST heterozygous littermates (Fig. 2b) and also normal appearance of these beta cells, which in both types of animals were packed with typical, dense-core and white halo secretory granules (Fig. 2c,d). Further morphological analyses showed that the numerical density of islets was similar in the pancreas of control and transgenic mice. However, the numerical density of beta cells, expressed as the ratio of total beta cell number to the total pancreas area, was reduced in RIP-REST mice (Table 1). Accordingly, the total insulin content of pancreas was twofold lower $(p<$ 0.01 ) in transgenic than in wild-type littermates (Table 1).

The ability of RIP-REST mice to regulate blood glucose levels was assessed in 3-month-old male animals during an intraperitoneal glucose tolerance test (IPGTT) (Fig. 3a). Compared with wild-type littermates, RIP-REST animals showed a significantly higher blood glucose concentration at $15(p<0.05), 30(p<0.01)$ and $60 \mathrm{~min}$ after glucose injection $(p<0.001)$. Parallel measurements of plasma insulin levels revealed similar fasting levels in control and RIP-REST mice (Fig. 3b). However, the release of insulin in the latter was significantly reduced at $15(p<0.05)$ and $30 \mathrm{~min}(p<$ 0.01 ) after glucose challenging (Fig. 3b). These data show that RIP-REST mice have reduced levels of pancreatic 


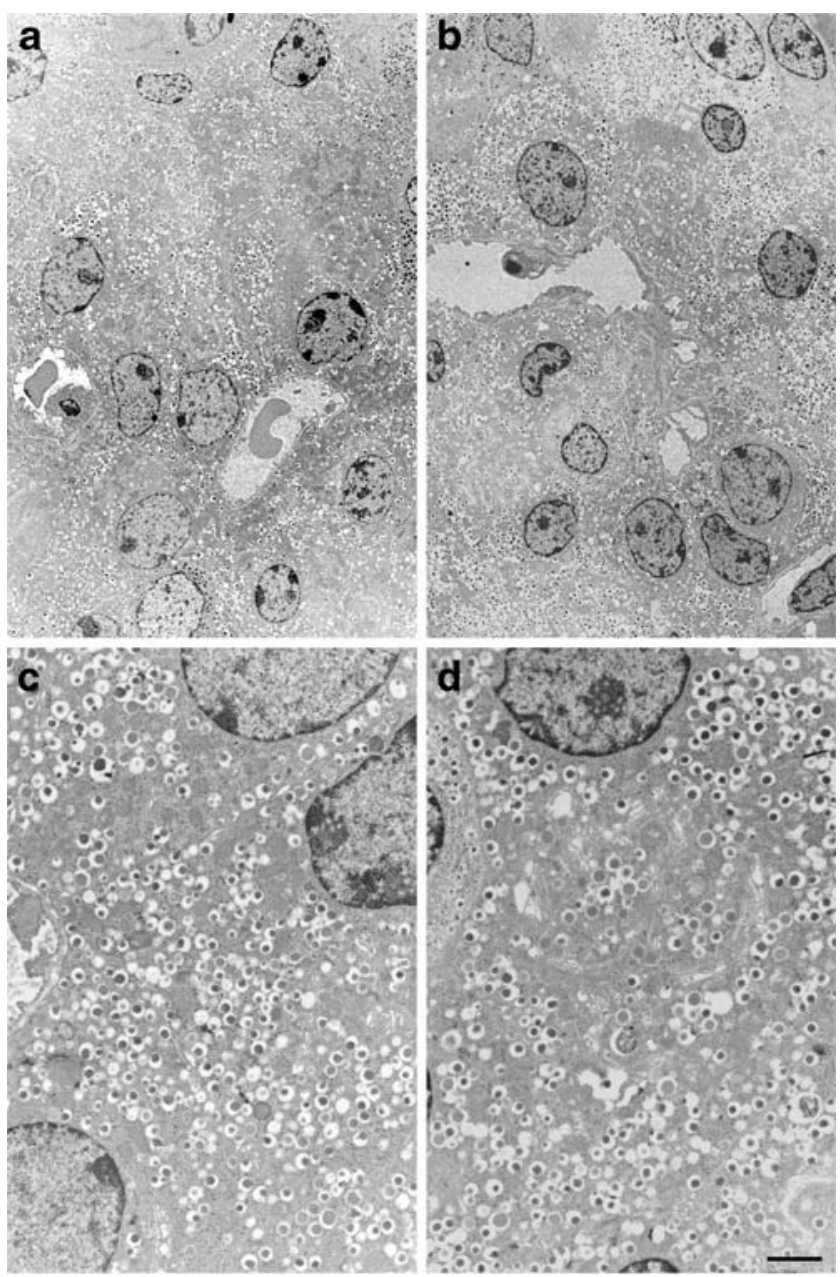

Fig. 2 RIP-REST mice feature ultrastructurally normal beta cells. Electron microscopy revealed normal organisation of beta cells within pancreatic islets of wild-type (a) and RIP-REST heterozygous littermates (b). Beta cells from wild-type (c) and RIP-REST mice (d) featured normal appearance and were packed with typical, densecore and white halo secretory granules. Bar: $5 \mu \mathrm{m}(\mathbf{a}, \mathbf{b}), 1.2 \mu \mathrm{m}(\mathbf{c}, \mathbf{d})$

insulin and are intolerant to glucose due to impaired secretory function of beta cells.

REST target genes are crucial for both first and second phases of insulin secretion To investigate this impairment, a

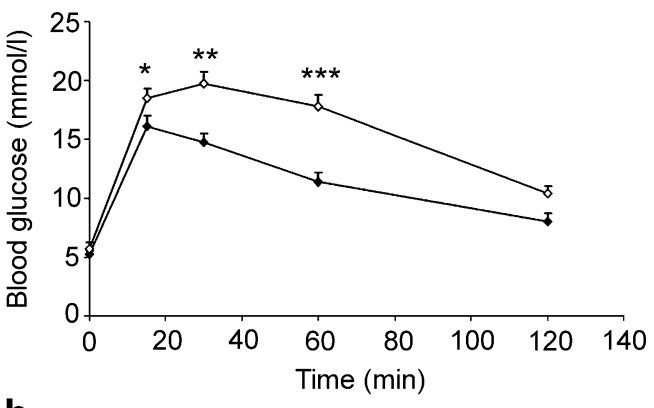

b

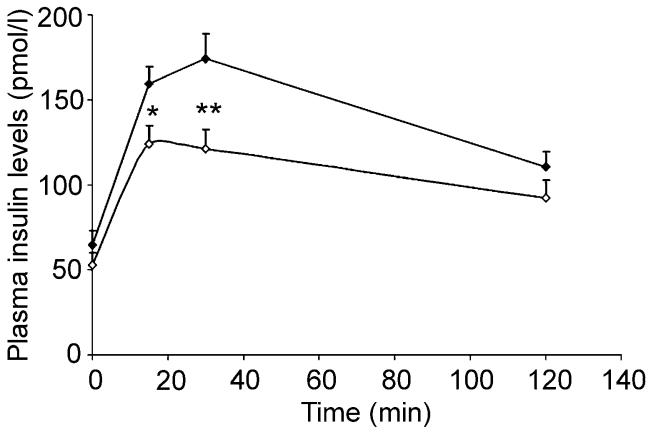

Fig. 3 RIP-REST mice are intolerant to glucose. a Blood glucose levels in 3-month-old wild-type (solid symbols) males $(n=10)$ and heterozygous RIP-REST (open symbols) littermates $(n=16)$ during an IPGTT. After $14 \mathrm{~h}$ fasting, blood samples were taken before $(t=0)$ and after $(t=15,30,60$ and $120 \mathrm{~min})$ intraperitoneal injection of glucose $(2 \mathrm{~g} / \mathrm{kg})$. Results are mean \pm SEM. ${ }^{*} p<0.05,{ }^{* *} p<0.01, * * * p<0.001$. b Plasma insulin levels were measured in 3-month-old male wild-type (solid symbols) $(n=6)$ and RIP-REST (open symbols) $(n=6)$ mice. Blood samples were taken at $0,15,30$ and $120 \mathrm{~min}$ of the IPGTT. Results are mean \pm SEM. ${ }^{*} p<0.05, * * p<0.01$

INS-1E-cells were infected with REST-encoding adenovirus (Ad-REST). Compared with control green fluorescent protein (GFP) transduction (Ad-GFP), ectopic REST expression did not alter insulin content $(400 \pm 60$ vs $423 \pm 39.6 \mathrm{pmol} / \mathrm{l}$, in GFP and REST-transduced cells, respectively) or basal insulin secretion (ESM Fig. 1). In contrast, it reduced insulin release in response to stimulating concentrations of either glucose, $\mathrm{KCl}$ or leucine, compared with GFP-transduced cells (ESM Fig. 1a). These data show that the $\mathrm{K}_{\mathrm{ATP}}$ channeldependent pathway of insulin secretion, triggered by $\mathrm{KCl}$, as

Table 1 Morphometric analysis of pancreas

\begin{tabular}{lcccc}
\hline Group & Pancreas weight (mg) & $\begin{array}{l}\text { Insulin content } \\
(\mathrm{pmol} / \mathrm{mg} \text { pancreas })\end{array}$ & $\begin{array}{l}\text { Islet numerical density } \\
(n \text { per cm })^{2}\end{array}$ & $\begin{array}{l}\text { Beta cell numerical density } \\
\left(n \text { per } \mathrm{cm}^{2}\right)\end{array}$ \\
\hline Wild-type & $239 \pm 22$ & $26 \pm 0.23$ & $62.1 \pm 2.6$ & $4,084 \pm 483$ \\
RIP-REST & $228 \pm 13$ & $13 \pm 0.28^{* *}$ & $65.7 \pm 8.4$ & $2,688 \pm 337^{*}$ \\
\hline
\end{tabular}

Values are expressed as mean $\pm \mathrm{SD}$

Number of mice per group: 4

${ }^{*} p<0.05, * * p<0.01$ versus WT 
well as the $\mathrm{K}_{\text {АTP }}$ channel-independent pathway, triggered by the non-metabolisable leucine analogue $\mathrm{BCH}$ [21], were both decreased in cells expressing REST. In the diazoxide experiments, the cells, in presence of $250 \mu \mathrm{mol} / 1$ diazoxide and $30 \mathrm{mmol} / 1 \mathrm{KCl}$, were stimulated with $2.5 \mathrm{mmol} / \mathrm{l}$ glucose and then with $15 \mathrm{mmol} / 1$ glucose. The second incubation at $15 \mathrm{mmol} / 1$ glucose, reflecting the amplifying effect of the sugar on insulin secretion [22], was significantly reduced in REST-expressing INS-1E cells (ESM Fig. 1a). Similar observations were made in REST and GFP-transduced mouse islets (ESM Fig. 1b), which also featured similar insulin contents $(73.8 \pm 6.4$ vs $66.9 \pm 5.4 \mathrm{pmol} / \mathrm{l}$, in GFP and RESTtransduced islets, respectively).

To ascertain whether REST affected both phases of insulin secretion, we perifused transduced mouse islets (Fig. 4a) and islets isolated from RIP-REST mice (Fig. 4b). Stimulation by $20 \mathrm{mmol} / \mathrm{l}$ glucose confirmed the REST-induced generalised impairment $(p<0.05)$ of the stimulus-secretion coupling during both first (time points 20 to $27 \mathrm{~min}$ ) and second phases (time points 28 to $44 \mathrm{~min}$ ).

REST does not affect plasma and mitochondrial membrane potentials or intracellular levels of $\mathrm{Ca}^{2+}$ To investigate the intracellular signalling leading to altered insulin release of REST-expressing INS-1E cells, we first studied the hyperpolarisation of the mitochondrial membrane, which results from the activation of mitochondrial metabolism. This hyperpolarisation induced by glucose was not affected when cells were infected with Ad-REST (ESM Fig. 2a). We then evaluated the cell membrane depolarisation resulting from the ATP-dependent closure of $\mathrm{K}_{\text {ATP }}$ channels. INS-1E cells expressing REST depolarised normally under glucose stimulation (ESM Fig. 2b). Since membrane depolarisation triggers $\mathrm{Ca}^{2+}$ influx through voltage-gated $\mathrm{Ca}^{2+}$ channels, we measured the cytoplasmic levels of this cation. We found that the expression of REST did not affect the glucoseinduced increase in intracellular $\mathrm{Ca}^{2+}$ (ESM Fig. 2c). These data suggest that REST does not alter the intracellular signalling that is activated by mitochondrial metabolism and leads to closure of $\mathrm{K}_{\mathrm{ATP}}$ channels, cell membrane depolarisation and elevation of cytosolic $\mathrm{Ca}^{2+}$.

Identification of functional RE-1 sequences We hypothesised that REST controls the expression of genes acting downstream of the elevation of intracellular $\mathrm{Ca}^{2+}$ and therefore selected, in a RE-1 database (http://www.bioinformatics.leeds. ac.uk/cgi-bin/RE1db/nrse.cgi) [7], the following putative targets: (1) the gene encoding the soluble $N$-ethylmaleimidesensitive factor attachment protein receptor (SNARE) protein SNAP25, which contains two consecutive RE-1s, referred to as RE-1.1 and RE-1.2 [7]; (2) the genes encoding the members of the $\mathrm{Ca}^{2+}$ sensor synaptotagmin family SYT II, SYT IV, SYT VI, SYT VII, SYT IX; and (3) the genes

\section{a}

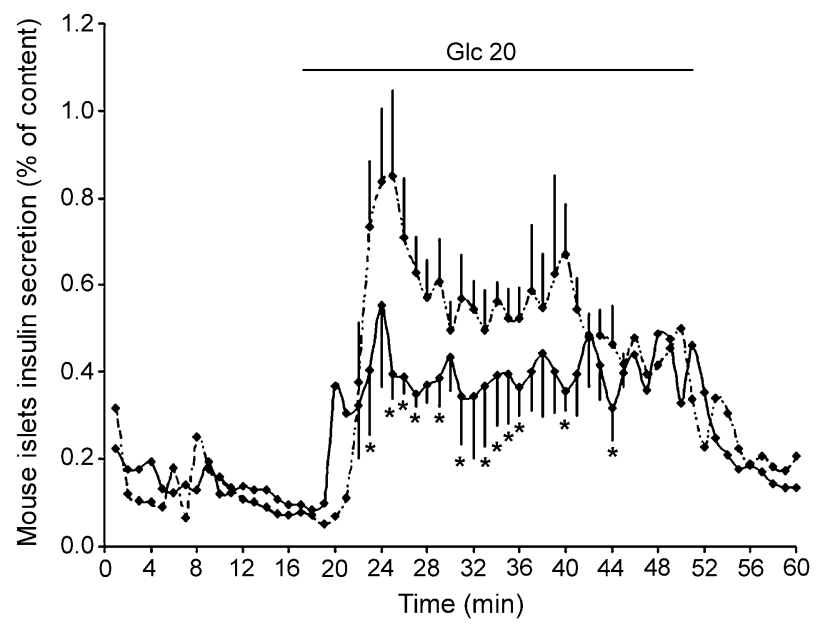

b

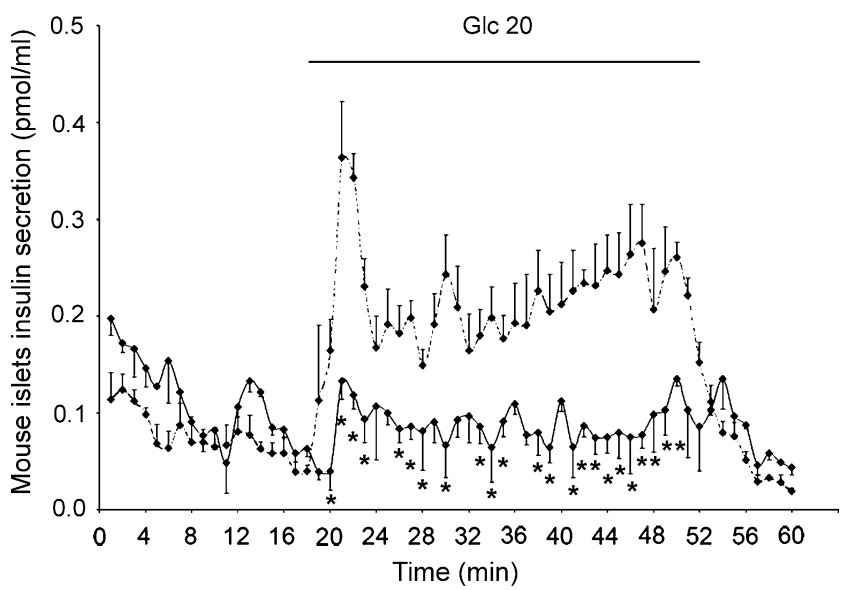

Fig. 4 Repression of REST target genes impairs the two phases of insulin release. a Insulin release of mouse islets transduced with AdGFP (dashed lines) and Ad-REST (solid lines) during perifusion experiments. After a $15 \mathrm{~min}$ period in presence of $2.5 \mathrm{mmol} / 1$ glucose, islets were stimulated for $30 \mathrm{~min}$ with $20 \mathrm{mmol} / \mathrm{l}$ glucose and then returned to $2.5 \mathrm{mmol} / 1$ glucose for $15 \mathrm{~min}$. Values are means \pm SEM. of three independent experiments. ${ }^{*} p<0.05$ for corresponding time points. b Insulin release of islets isolated from wild-type (dashed lines) and RIP-REST (solid lines) mice during perifusion experiments. After a $15 \mathrm{~min}$ period in presence of $2.5 \mathrm{mmol} / 1$ glucose, islets were stimulated for $30 \mathrm{~min}$ with $20 \mathrm{mmol} / 1$ glucose and then returned to $2.5 \mathrm{mmol} / 1$ glucose for $15 \mathrm{~min}$. Values are means $\pm \mathrm{SEM}$ of three independent experiments. ${ }^{*} p<0.05,{ }^{* *} p<0.01$ for corresponding time points. Glc, glucose

coding for the $N$-ethylmaleimide-sensitive factor (NSF), for UNC-18 homologue 1 (MUNC-18-1) and for complexin II, which participate in the formation and stabilisation of the SNARE complex. The $21 \mathrm{bp}$ human RE-1 sequences associated to these genes were compared with those of consensus RE-1 and of the known CX36 RE-1 [11]. All sequences, except that of MUNC18-1, were closely homologous to the consensus one and displayed a typical core [23] consisting of two invariant domains (Fig. 5a).

The in situ binding activity of these RE-1s in RESTexpressing INS-1E cells was assessed by a chromatin 
a

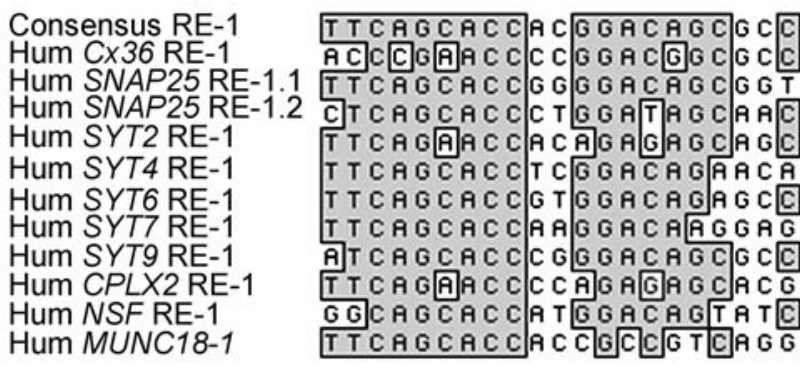

b

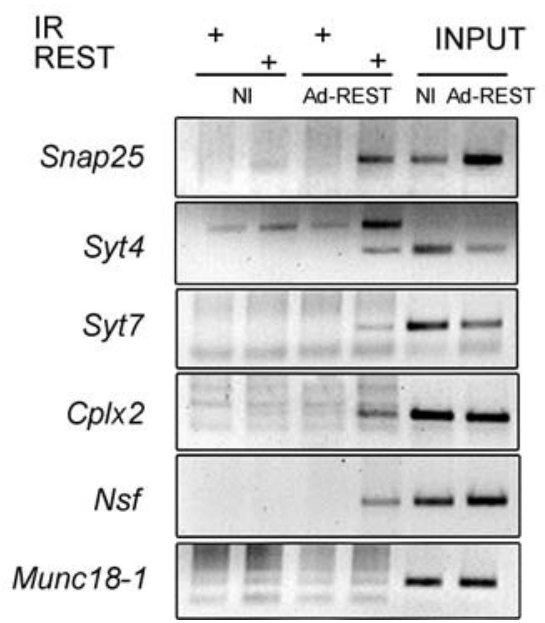

Fig. 5 Several genes coding for proteins of the exocytotic machinery have functional RE-1 binding sites. a Alignment of identified human (Hum) RE-1 sequences with consensus RE-1 and the functional Cx36 RE-1. The SNAP25 gene contains two consecutive RE-1s referred to as RE-1.1 and RE-1.2. b Chromatin immunoprecipitation assay comparing wild-type (NI) and REST-transduced INS-1E cells (Ad-REST). PCR amplification of the indicated genes showed enrichment of the RE-1 flanking sequences in chromatin immunoprecipitated with antiREST antibodies (REST) compared with irrelevant anti-SREBP-1 antibodies (IR). Non-precipitated chromatin (INPUT) is shown as control. Results are representative of three independent experiments

immunoprecipitation assay. The RE-1s of the Snap25, Syt4, Syt7, Nsf and Cplx2 genes were immunoprecipitated with the antibodies against REST (Fig. 5b), confirming the functional properties of these RE-1 sequences. In contrast the RE-1 of Munc18-1 was not enriched in the cells transduced for REST, consistent with the more variable sequence of this RE-1 motif (Fig. 5a).

RESTrepresses a subset of genes implicated in exocytosis The effect of REST binding to RE-1s was assessed on several endogenous transcripts of INS-1E cells. A transcriptional repression was observed for the Snap25, Syt4, Syt7, Syt 9 and Cplx2 genes, but not for the genes coding for NSF and MUNC18-1 (Fig. 6a). The signal for the Syt7 gene, which is subjected to alternative splicing [24], corresponds to the most abundant $S y t 7 a$ splice variant. The negative regulation of $C x 36$ [11] is shown as a control. The expression levels of several genes lacking RE-1, including those coding for t- a

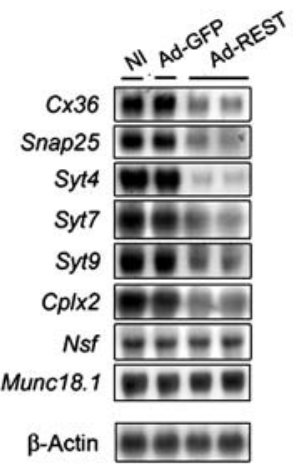

b

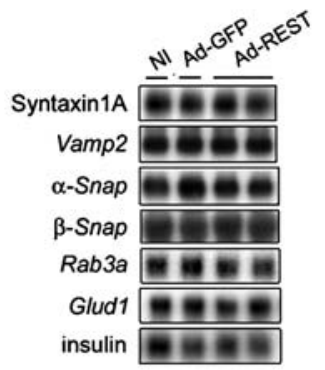

$\beta$-Actin $\mathrm{e}=\mathrm{e}$

C
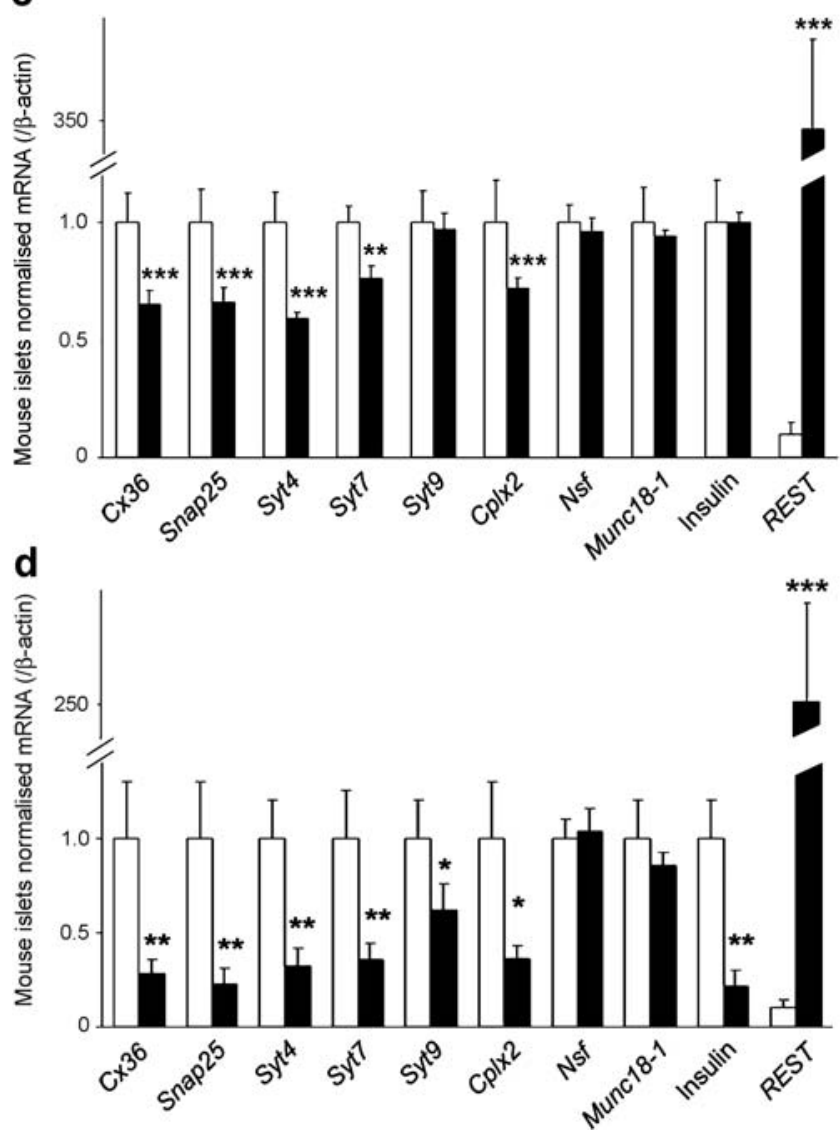

Fig. 6 REST downregulates the expression of several genes coding for proteins of the exocytotic machinery. $\mathbf{a}, \mathbf{b}$ Northern blot of mRNA from wild-type (NI) and transduced (Ad-GFP, Ad-REST) INS-1E cells, displaying (a) the transcriptional downregulation of genes with identified RE-1 sequence and (b) the transcript levels of genes that lack RE-1 and which encode other proteins of the exocytotic machinery, insulin and mitochondrial Glud1. $\beta$-actin mRNA signals served as internal control. c Quantitative RT-PCR analysis of mRNA levels of putative target genes in mouse islets transduced with Ad-GFP (white columns) and Ad-REST (black columns). Results are mean \pm SEM of four independent experiments. d Quantitative RT-PCR analysis of mRNA levels of putative REST target genes from islets of wild-type (white columns) $(n=6)$ and RIP-REST (black columns) $(n=$ 10) mice. Results are mean \pm SEM. ${ }^{*} p<0.05,{ }^{*} p<0.01,{ }^{* * *} p<0.001$ 
SNARE syntaxin $1 \mathrm{~A}, \mathrm{v}-\mathrm{SNARE}$ vesicle-associated membrane protein 2 (VAMP2), $\alpha$ - and $\beta$-soluble NSF attachment protein, small GTP-binding protein RAB3A, member RAS oncogene family (RAB3A), Gludl gene encoding mitochondrial glutamate dehydrogenase (GDH), and insulin were not modulated by REST (Fig. 6b). Quantitative RTPCR revealed a similar transcription pattern in islets transduced for REST (Fig. 6c) or isolated from RIP-REST mice (Fig. 6d). However, in contrast to the findings in transiently transduced INS-1E cells and islets, the constitutive expression of REST in islets from transgenic mice was also associated with lower levels of insulin mRNA (Fig. 6d). To assess whether these transcriptional changes affected the levels of the cognate proteins, we performed western blots with total extracts of transduced INS-1E cells (Fig. 7a) and of islets isolated from RIP-REST mice, where REST was declared as a $210 \mathrm{kDa}$ immunoreactive band (Fig. 7b). In both cases, the presence of REST decreased the levels of SNAP25 and SYT IV proteins, detected as immunoreactive bands of 25 and $45 \mathrm{kDa}$, respectively. CX36 is shown as a positive control [11].

a

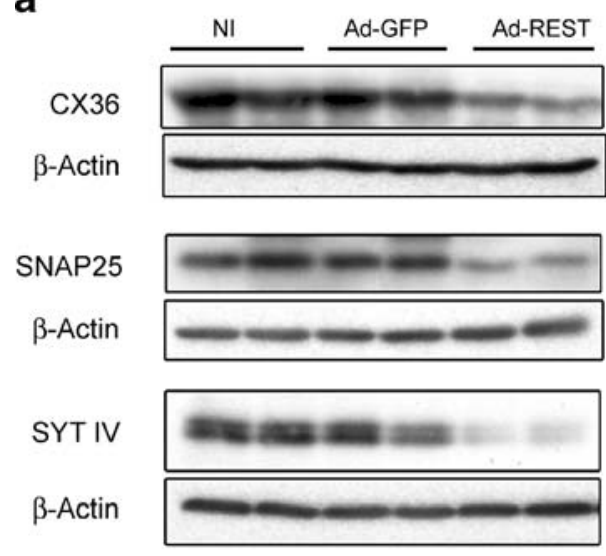

b

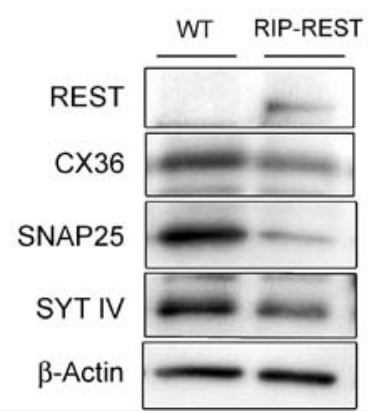

Fig. 7 REST downregulates the expression of selected protein. a Immunoblotting of total protein from wild-type (NI) and transduced (Ad-GFP, Ad-REST) INS-1E cells showed the decreased levels of SNAP-25 and SYT IV proteins in REST-expressing cells. CX36 levels are shown as a positive control. b Immunoblotting of total proteins from islets isolated from wild-type (WT) $(n=3)$ and RIP-REST $(n=3)$ mice. An immunoreactive band for REST $(210 \mathrm{kDa})$ was found in RIP-REST but not in control islets. CX36, SNAP25 and SYT IV abundance were reduced in RIP-REST animals
SYT IV or SYT VII silencing inhibits hormone secretion To clarify the role of SYT IV and SYT VII in insulin secretion, we used a plasmid directing the expression of a specific siRNA and of hGH as a reporter gene. We compared the effect of three constructs, containing either a siRNA specific to the Syt4 isoform (siRNA Syt4), to all Syt7 splice variants (siRNA Syt7) or, as a negative control, to human REST (siRNA REST). The silencing efficiency of each construct was checked at the transcript levels of target genes fused to luciferase reporter gene (data not shown). The effect of SYT silencing on hGH secretion was assessed in transfected INS-1E cells, stimulated with a mixture of $15 \mathrm{mmol} / 1$ glucose, $10 \mu \mathrm{mol} / \mathrm{l}$ forskolin and $100 \mu \mathrm{mol} / 1$ IBMX (Fig. 8). Under these conditions, the control cells transfected with pXGH alone showed a fourfold increase in the release of hGH. The selective knockdown of either SYT IV or SYT VII did not significantly alter basal secretion, but inhibited hGH release by 60 and $50 \%$, respectively (Fig. 8). The transfection of $\mathrm{pXGH}$ together with a plasmid coding for human REST, also resulted in a $40 \%$ decrease in the stimulated hGH secretion, whereas the transfection of siRNA REST did not alter hGH release. These data show that SYT IV and SYT VII contribute to the control of insulin release.

\section{Discussion}

Through its loss of function at different stages of neural differentiation, the transcriptional repressor REST plays a

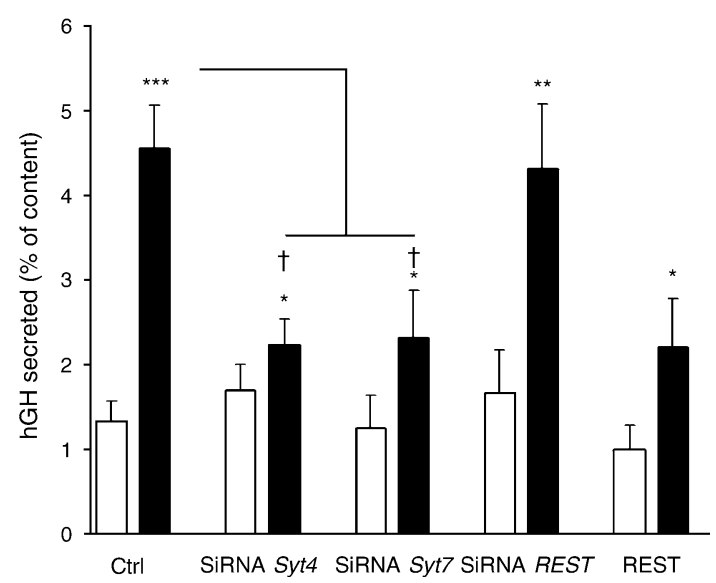

Fig. 8 SYT IV or SYT VII silencing inhibits hormone secretion. hGH release in INS-1E cells transiently transfected with a plasmid encoding hGH alone (Control [Ctrl]) or with a plasmid encoding hGH together with either the siRNA Syt4, the siRNA Syt7 or the siRNA REST. Secretion was monitored under basal conditions (white columns) and after stimulation by $15 \mathrm{mmol} / \mathrm{l}$ glucose plus $10 \mu \mathrm{mol} / 1$ forskolin and $100 \mu \mathrm{mol} / \mathrm{l}$ IBMX (black columns). Silencing of either SYT isoforms or REST expression reduced the stimulated $\mathrm{hGH}$ release. Results are mean \pm SEM of three independent experiments. $* p<0.05, * * p<0.01$ and $* * * p<0.001$ versus values of respective basal conditions; $\dagger p<$ 0.01 versus values of stimulated control condition 
strategic role in the specification of the neuronal phenotype, [25]. The absence of REST from mature pancreatic beta cells also assigns to this cell type a specific pattern of genes, termed neuronal traits [10]. Recently, these traits have been implicated in the functioning of a transformed pancreatic beta cell line [1]. However, it has not been elucidated whether any of these genes is directly involved in primary beta cell function and if so, through which mechanism. In the present study, we show that the target genes of REST are crucial for proper function of adult primary beta cells, inasmuch as a gain of REST function impairs first and second phases of insulin secretion. Our data suggest that REST controls a step of the stimulus-secretion coupling pathway, which is downstream of the elevation of intracellular $\mathrm{Ca}^{2+}$ and common to both first and second phases of insulin secretion. We hypothesised that it may be related to vesicle trafficking and/or fusion. Accordingly, we found that REST repressed the expression of several genes coding for proteins of the exocytotic machinery, including SNAP25, SYT IV, SYT VII, SYT IX and complexin II. The exocytosis of insulin-containing LDCV resembles that of neuronal synaptic vesicles [26] and employs a similar broad set of proteins, each of which plays a precise role. In particular, a direct implication in the control of insulin secretion has been established for several members of the exocytotic machinery, including SNAP25 [27], NSF [28], MUNC18-1 [29] and both SYT V and SYT IX [30]. However, the role of SYT IV and SYT VII in neurons and pancreatic beta cells is still a matter of debate. In neuroendocrine PC12 cells, SYT IV has been identified as an essential component for the maturation of secretory granules [31]. This protein has also been reported to play a role in the stabilisation of the fusion pore and in the choice between kiss-and-run and full fusion events, for both synaptic vesicles of PC12 and LDCV of MIN-6 cells [32, 33]. In PC12 cells, SYT VII has also been implicated in the exocytosis of synaptic vesicle [19, 34, 35], whereas in beta cells this protein may be implicated in endocytotic traffic and insulin exocytosis [36, 37]. Using specific siRNAs, we confirm the recently published data on the role of SYT VII in insulin secretion [37] and show that SYT IV also plays a significant role in the control of insulin release from INS-1E cells.

The integrity of the exocytotic machinery is critical for glucose homeostasis, as observed in the Goto-Kakisaki rat model of type 2 diabetes and in type 2 diabetic patients, in both of which the expression of SNARE proteins is decreased $[38,39]$. In view of the present knowledge on granule dynamics and distinct pools, it has been speculated that the proteins of the exocytotic machinery that are implicated in the rate-limiting priming of secretory granules are strong candidates for the triggering of beta cell dysfunctions associated with type 2 diabetes [40]. In the RIP-REST transgenic mice that specifically express REST in beta cells, expression of multiple REST target genes, including those coding for the major proteins controlling exocytosis, was decreased. This model provides a unique opportunity to assess, in vivo, the function of REST-dependent genes. We observed that these genes are critical for insulin secretion, inasmuch as their downregulation resulted in loss of glucose-dependent and glucose-independent insulin release to a degree sufficient to cause glucose intolerance. In these mice, the expression of REST did not alter the architecture of pancreatic islets, but induced a reduction in the number of beta cells. This effect is consistent with the anti-proliferative action of REST, previously reported in tumoral transformation [41] and human neointimal hyperplasia [9]. The reduced number of cells correlated with reduced expression of the insulin gene and lower pancreatic content of the hormone, which was not observed in INS1-E cells acutely transduced for REST. This lower rate of insulin production may be accounted for by the decreased insulin exocytosis rate and/or the long term REST-induced repression of key factors, such as the protein tyrosine phosphatase, receptor type, N (ICA512). Upon exocytosis, this LDCV-associated protein is cleaved and stimulates insulin synthesis through a retrograde pathway in order to adjust insulin production to its exocytosis [42]. The Ica512 gene is a bona fide RE-1 containing REST target gene, whose expression was decreased in both REST-expressing INS-1E cells and islets of RIP-REST transgenic mice (data not shown).

According to recent data on the genome-wide chromatin occupancy mediated by REST in non neuroendocrine cells, new target genes implicated in different cell functions remain to be found and their effects evaluated [43, 44]. The multiplicity of these genes and their functional interactions make it necessary to perform comprehensive studies using gene array-based analyses of RIP-REST mice. Such studies should identify which of these genes is key to beta cell identity, insulin secretion and beta cell survival. Such a comprehensive analysis was beyond the scope of our study and will be the topic of future experiments.

In summary, using an innovative approach of ectopic REST expression in beta cells, we have identified several target genes that significantly contribute to the in vitro and in vivo control of glucose-stimulated insulin secretion. Our findings document the physiological importance of the native downregulation of REST in beta cells and possibly in other neuroendocrine cells [45] with a view to maintaining normal secretion by regulating the levels of key exocytotic proteins. Our findings point to the RIP-REST transgenic mice as a pertinent model for the identification of other REST target genes that may play a critical role in the pathophysiology of glucose intolerance and, possibly, of diabetes.

Acknowledgements The work of our teams was supported by grants from the Swiss National Science Foundation (31-109530, 31-107644/1, 31-109402, 31-109281/1 and 3200B0-101746), the Juvenile Diabetes 
Foundation International (1-2005-46 and 1-2007-158), the Placide Nicod Foundation, the Octav and the Marcella Botnar Foundation, the Novartis Foundation, The Emma Muschamp Foundation, The Endocrinology Geneva Foundation, Novo Nordisk and the Geneva Program for Metabolic Diseases.

Duality of interest The authors declare that there is no duality of interest associated with this manuscript.

\section{References}

1. Abderrahmani A, Niederhauser G, Plaisance V, Haefliger JA, Regazzi R, Waeber G (2004) Neuronal traits are required for glucose-induced insulin secretion. FEBS Lett 565:133-138

2. Chong JA, Tapia-Ramirez J, Kim S et al (1995) REST: a mammalian silencer protein that restricts sodium channel gene expression to neurons. Cell 80:949-957

3. Schoenherr CJ, Anderson DJ (1995) The neuron-restrictive silencer factor (NRSF): a coordinate repressor of multiple neuron-specific genes. Science 267:1360-1363

4. Li L, Suzuki T, Mori N, Greengard P (1993) Identification of a functional silencer element involved in neuron-specific expression of the synapsin I gene. Proc Natl Acad Sci USA 90:1460-1464

5. Bessis A, Champtiaux N, Chatelin L, Changeux JP (1997) The neuron-restrictive silencer element: a dual enhancer/silencer crucial for patterned expression of a nicotinic receptor gene in the brain. Proc Natl Acad Sci USA 94:5906-5911

6. Wood IC, Roopra A, Buckley NJ (1996) Neural specific expression of the $\mathrm{m} 4$ muscarinic acetylcholine receptor gene is mediated by a RE1/NRSE-type silencing element. J Biol Chem 271:14221-14225

7. Bruce AW, Donaldson IJ, Wood IC et al (2004) Genome-wide analysis of repressor element 1 silencing transcription factor/ neuron-restrictive silencing factor (REST/NRSF) target genes. Proc Natl Acad Sci U S A 101:10458-10463

8. Kuwahara K, Saito Y, Takano M et al (2003) NRSF regulates the fetal cardiac gene program and maintains normal cardiac structure and function. Embo J 22:6310-6321

9. Cheong A, Bingham AJ, Li J et al (2005) Downregulated REST transcription factor is a switch enabling critical potassium channel expression and cell proliferation. Mol Cell 20:45-52

10. Atouf F, Czernichow P, Scharfmann R (1997) Expression of neuronal traits in pancreatic beta cells. Implication of neuronrestrictive silencing factor/repressor element silencing transcription factor, a neuron-restrictive silencer. J Biol Chem 272:1929-1934

11. Martin D, Tawadros T, Meylan L et al (2003) Critical role of the transcriptional repressor neuron-restrictive silencer factor in the specific control of connexin36 in insulin-producing cell lines. $\mathrm{J}$ Biol Chem 278:53082-53089

12. Abderrahmani A, Steinmann M, Plaisance V et al (2001) The transcriptional repressor REST determines the cell-specific expression of the human MAPK8IP1 gene encoding IB1 (JIP-1). Mol Cell Biol 21:7256-7267

13. Herrera PL, Huarte J, Zufferey R et al (1994) Ablation of islet endocrine cells by targeted expression of hormone-promoter-driven toxigenes. Proc Natl Acad Sci U S A 91:12999-13003

14. Charollais A, Serre V, Mock C, Cogne F, Bosco D, Meda P (1999) Loss of alpha 1 connexin does not alter the prenatal differentiation of pancreatic beta cells and leads to the identification of another islet cell connexin. Dev Genet 24:13-26

15. Allagnat F, Martin D, Condorelli DF, Waeber G, Haefliger JA (2005) Glucose represses connexin36 in insulin-secreting cells. J Cell Sci 118:5335-5344
16. Carobbio S, Ishihara H, Fernandez-Pascual S, Bartley C, MartinDel-Rio R, Maechler P (2004) Insulin secretion profiles are modified by overexpression of glutamate dehydrogenase in pancreatic islets. Diabetologia 47:266-276

17. Merglen A, Theander S, Rubi B, Chaffard G, Wollheim CB, Maechler P (2004) Glucose sensitivity and metabolism-secretion coupling studied during two-year continuous culture in INS-1E insulinoma cells. Endocrinology 145:667-678

18. Zhang Q, Fukuda M, Van Bockstaele E, Pascual O, Haydon PG (2004) Synaptotagmin IV regulates glial glutamate release. Proc Natl Acad Sci USA 101:9441-9446

19. Fukuda M, Kanno E, Satoh M, Saegusa C, Yamamoto A (2004) Synaptotagmin VII is targeted to dense-core vesicles and regulates their $\mathrm{Ca}^{2+}$-dependent exocytosis in $\mathrm{PC} 12$ cells. J Biol Chem 279:52677-52684

20. Abderrahmani A, Cheviet S, Ferdaoussi M, Coppola T, Waeber G, Regazzi R (2006) ICER induced by hyperglycemia represses the expression of genes essential for insulin exocytosis. Embo J 25:977-986

21. Liu YJ, Cheng H, Drought H, MacDonald MJ, Sharp GW, Straub SG (2003) Activation of the KATP channel-independent signaling pathway by the nonhydrolyzable analog of leucine, BCH. Am J Physiol Endocrinol Metab 285:E380-E389

22. Gembal M, Detimary P, Gilon P, Gao ZY, Henquin JC (1993) Mechanisms by which glucose can control insulin release independently from its action on adenosine triphosphate-sensitive $\mathrm{K}+$ channels in mouse B cells. J Clin Invest 91:871-880

23. Schoenherr CJ, Paquette AJ, Anderson DJ (1996) Identification of potential target genes for the neuron-restrictive silencer factor. Proc Natl Acad Sci USA 93:9881-9886

24. Fukuda M, Ogata Y, Saegusa C, Kanno E, Mikoshiba K (2002) Alternative splicing isoforms of synaptotagmin VII in the mouse, rat and human. Biochem J 365:173-180

25. Ballas N, Grunseich C, Lu DD, Speh JC, Mandel G (2005) REST and its corepressors mediate plasticity of neuronal gene chromatin throughout neurogenesis. Cell 121:645-657

26. Burgoyne RD, Morgan A (2003) Secretory granule exocytosis. Physiol Rev 83:581-632

27. Sadoul K, Lang J, Montecucco C et al (1995) SNAP-25 is expressed in islets of Langerhans and is involved in insulin release. J Cell Biol 128:1019-1028

28. Vikman J, Ma X, Tagaya M, Eliasson L (2003) Requirement for $\mathrm{N}$-ethylmaleimide-sensitive factor for exocytosis of insulin-containing secretory granules in pancreatic beta-cells. Biochem Soc Trans 31: 842-847

29. Zhang W, Efanov A, Yang SN et al (2000) Munc-18 associates with syntaxin and serves as a negative regulator of exocytosis in the pancreatic beta-cell. J Biol Chem 275:41521-41527

30. Iezzi M, Kouri G, Fukuda M, Wollheim CB (2004) Synaptotagmin V and IX isoforms control $\mathrm{Ca}^{2+}$-dependent insulin exocytosis. J Cell Sci 117:3119-3127

31. Ahras M, Otto GP, Tooze SA (2006) Synaptotagmin IV is necessary for the maturation of secretory granules in PC12 cells. J Cell Biol 173:241-251

32. Wang CT, Lu JC, Bai J et al (2003) Different domains of synaptotagmin control the choice between kiss-and-run and full fusion. Nature 424:943-947

33. Tsuboi T, Rutter GA (2003) Multiple forms of "kiss-and-run" exocytosis revealed by evanescent wave microscopy. Curr Biol 13:563-567

34. Wang P, Chicka MC, Bhalla A, Richards DA, Chapman ER (2005) Synaptotagmin VII is targeted to secretory organelles in PC12 cells, where it functions as a high-affinity calcium sensor. Mol Cell Biol 25:8693-8702

35. Sugita S, Han W, Butz S et al (2001) Synaptotagmin VII as a plasma membrane $\mathrm{Ca}(2+)$ sensor in exocytosis. Neuron 30:459-473 
36. Monterrat C, Grise F, Benassy MN, Hemar A, Lang J (2007) The calcium-sensing protein synaptotagmin 7 is expressed on different endosomal compartments in endocrine, neuroendocrine cells or neurons but not on large dense core vesicles. Histochem Cell Biol $127: 625-632$

37. Gauthier BR, Duhamel DL, Iezzi M et al (2008) Synaptotagmin VII splice variants a, $\beta$, and $d$ are expressed in pancreatic $\beta$-cells and regulate insulin exocytosis. FASEB J 22:194-206

38. Gaisano HY, Ostenson CG, Sheu L, Wheeler MB, Efendic S (2002) Abnormal expression of pancreatic islet exocytotic soluble $\mathrm{N}$-ethylmaleimide-sensitive factor attachment protein receptors in Goto-Kakizaki rats is partially restored by phlorizin treatment and accentuated by high glucose treatment. Endocrinology 143:42184226

39. Ostenson CG, Gaisano H, Sheu L, Tibell A, Bartfai T (2006) Impaired gene and protein expression of exocytotic soluble $\mathrm{N}$ ethylmaleimide attachment protein receptor complex proteins in pancreatic islets of type 2 diabetic patients. Diabetes 55:435-440
40. Rorsman P, Renstrom E (2003) Insulin granule dynamics in pancreatic beta cells. Diabetologia 46:1029-1045

41. Westbrook TF, Martin ES, Schlabach MR et al (2005) A genetic screen for candidate tumor suppressors identifies REST. Cell 121:837-848

42. Trajkovski M, Mziaut H, Altkruger A et al (2004) Nuclear translocation of an ICA512 cytosolic fragment couples granule exocytosis and insulin expression in $\beta$-cells. J Cell Biol 167:10631074

43. Otto SJ, McCorkle SR, Hover J et al (2007) A new binding motif for the transcriptional repressor REST uncovers large gene networks devoted to neuronal functions. J Neurosci 27:6729-6739

44. Johnson DS, Mortazavi A, Myers RM, Wold B (2007) Genomewide mapping of in vivo protein-DNA interactions. Science 316:1497-1502

45. Bruce AW, Krejci A, Ooi L et al (2006) The transcriptional repressor REST is a critical regulator of the neurosecretory phenotype. $\mathrm{J}$ Neurochem 98:1828-1840 